\title{
The carpal tunnel syndrome in leprosy: a long term follow up of steroids versus surgical decompression for median nerve neuritis in leprosy
}

\author{
Imran Sajid $^{\mathrm{a}}$, Mamta Arora ${ }^{\mathrm{b}}$, Etisha Nawani ${ }^{\mathrm{c}}$ \& \\ Kameshwar Nath Mishra ${ }^{\mathrm{d}}$ \\ a Associate Professor, Department of Orthopaedics, F.H. Medical College \\ and Hospital, Etmadpur, Agra, India \\ ORCID: https://orcid.org/0000-0001-6162-5782 \\ ${ }^{\mathrm{b}}$ Scientist, ICMR-National JALMA Institute for Leprosy \& Other \\ Mycobacterial Disease, India \\ ${ }^{\mathrm{c}}$ Assistant Professor, Department of Microbiology, F.H. Medical College \\ and Hospital, Etmadpur, Agra, India \\ ${ }^{\mathrm{d}}$ Physiotherapist, Senior Technical Officer, ICMR-National JALMA Institute \\ for Leprosy \& Other Mycobacterial Disease, Agra, India
}

Submitted 25 May 2021; Accepted 10 August 2021

\begin{abstract}
Summary Leprosy is a stigmatizing and neglected tropical disease still prevalent in various countries of the world. According to WHO reports from 159 countries, 208,619 new leprosy cases were reported globally in 2018, of which Brazil, India, and Indonesia accounted for $79.6 \%$. With the preference of $M$. leprae for cooler areas, peripheral nephropathy of the hand and feet are commonly seen in leprosy patients. Peripheral nerve involvement may result in the development of deformities. The ulnar nerve is commonly involved followed by median nerve, common peroneal nerve, facial nerve and the radial nerve in descending order. High doses of steroids are commonly given in peripheral neuropathies, but $70-75 \%$ cases still develop deformity with this treatment. Surgical decompression of involved nerves, though not so common, is another modality attempted for nerve damage prevention. In the present study, we compared steroid therapy alone with steroids plus surgical decompression, for carpal tunnel syndrome in leprosy cases.

Methods 52 patients with involvement of 70 median nerves (18 bilateral) were enrolled. They had palpable median nerves, along with sensory and motor loss. 16 patients were lost to follow up by 2 years, so that 36 patients with 50 median nerves (14 bilateral) remained for review. These cases were randomly divided into two groups: one group was given steroids while the second group was given steroids along with surgical nerve decompression. The results were evaluated for improvement or deterioration of the sensory and motor symptoms, along with pain.
\end{abstract}

Correspondence to: Imran Sajid, Associate Professor, Department of Orthopaedics, F.H. Medical College and Hospital, Etmadpur, Agra, India (e-mail: imransajid60@gmail.com)

(C) The author(s). This article is Open Access under CC BY 4.0 
Conclusion The results support the proposition that surgical decompression of the nerve together with steroid treatment, is a better option to prevent the progression of deformities due to median nerve involvement, than steroids alone.

Keywords: Leprosy, median nerve, decompression, steroids, sensory, motor

\section{Introduction}

The median nerve is the second most common nerve to be affected in leprosy. It clinically presents as the carpal tunnel syndrome, the wrist being the usual site of its involvement in leprosy. When the median nerve is involved, the inflammation builds up in the nerve tissue causing its entrapment internally due to oedema and externally due to its anatomical position, resulting in nerve tissue compression. This process of inflammation clinically manifests in symptoms like paresthesia, sensory loss, motor damage (in the form of paralysis of abductor pollicis and opponens pollicis, ultimately leading to loss of abduction and opposition of the thumb) along with thenar muscle wasting. This presents as functional loss affecting the pinch and grasp functions. One of the early signs often noted is tenderness when pressed on the inflamed nerve.

Once paralysis is established, it is very difficult to achieve complete recovery by any modality be it medical or surgical. Hence, early detection and adequate treatment of neural impairment is of paramount importance for the prevention of disabilities in leprosy. ${ }^{1}$ To achieve good results, a combination of medical and surgical approaches, along with well supported physiotherapy is the need of the hour. The combination of steroid therapy along with surgical decompression has been commonly used for ulnar nerve neuritis with good results, ${ }^{2,3}$ though long term results have not been reported. The same is true for the median nerve.

\section{Methods}

In this study, 52 patients ( 34 with unilateral and 18 with bilateral involvement, totalling 70 median nerves) were enrolled between 2015 to 2019 at the OPD of the National JALMA Institute and at the Department of Orthopaedics at F.H. Medical College and hospital. The age range of patients was 15 to 51 years. These cases had palpable median nerves along with sensory and motor impairment. Patients had complaints of numbness, paresthesia, sensory loss and motor weakness in the areas/muscles supplied by median nerve. The median nerve was palpable and tender over the wrist area.

Basic investigations, including $\mathrm{CBC}$, blood sugar, blood pressure were done for all the patients and only patients with normal values were included in this study.

The patients were randomized to groups A and B. Both groups had an equal number of median nerves ( 25 each) with Group A having 12 females and 13 males while Group B had 10 females and 15 males. Anti-leprosy treatment was continued in both groups. For patients with bilateral involvement, the right side was allocated to one group by random selection, while the left side was then placed in the other group.

The modalities of treatment for Group A-Treatment with steroids alone (Medical Group). They were given prednisolone $40 \mathrm{mg}$ daily for 15 days, which was then tapered down by $5 \mathrm{mg}$ every 7 days till it was reduced to $10 \mathrm{mg}$; then $10 \mathrm{mg}$ continued till the end of 6 months. The intensity of pain was noted at each follow-up visit using the Visual Analogue Scale (VAS).

Group B patients were given a steroid course as in group A, but also underwent open surgical decompression of the median nerve at the carpal tunnel (Surgical Group). 


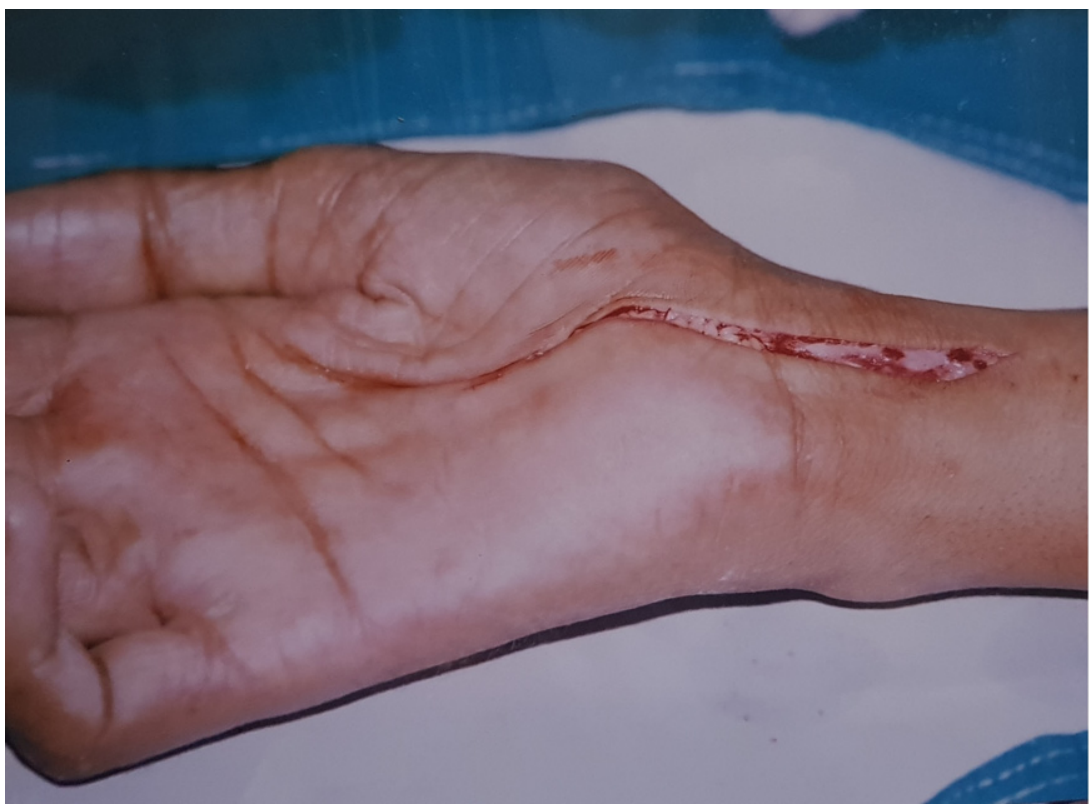

Figure 1. Incision for carpal tunnel release.

\section{Decompression of the median nerve}

After careful pre-anesthetic checkup, patients were undertaken for surgery. Patients were kept in the supine position with the upper limb on an arm support and an axillary block was given as regional anesthesia.

Incision for open carpal tunnel release was made at the wrist crease and was limited distally at the level of intersection of the line from the proximal extension of the radial border of the ring finger with the Kaplan Cardinal Line (KCL) (Figure 1). Superficial and deep facia were incised. The palmaris longus muscle was retracted to expose the median nerve. All the deep facial bands were cut and de-roofing of the tunnel was done to allow the free movement of swollen median nerve.

The longitudinal incision gave access to the epineurium \& perineum (Figure 2). The nerve was opened like a book to release the internal compression due to inflammation.

The skin was closed using 3-0 skin sutures. Antibiotics for 3 days were given post operatively. Skin sutures were removed after 1 week but steroids and anti-leprosy treatment continued as per protocol.

The profiles of patients/nerves included in both groups are shown in Table 1.

\section{Follow up}

After completion of treatment/surgery, patients were followed at an interval of one month for three months and then every 6 months up to 2 years. 16 patients were lost to follow up, so at the final follow up after 2 years there were 36 patients with 50 median nerves ( 14 bilateral cases) which were ultimately included in the study.

The patients were evaluated by assessing the nerve functions in terms of motor and sensory recovery. Nerve function was assessed by Voluntary Muscle Testing (VMT) and Sensory 


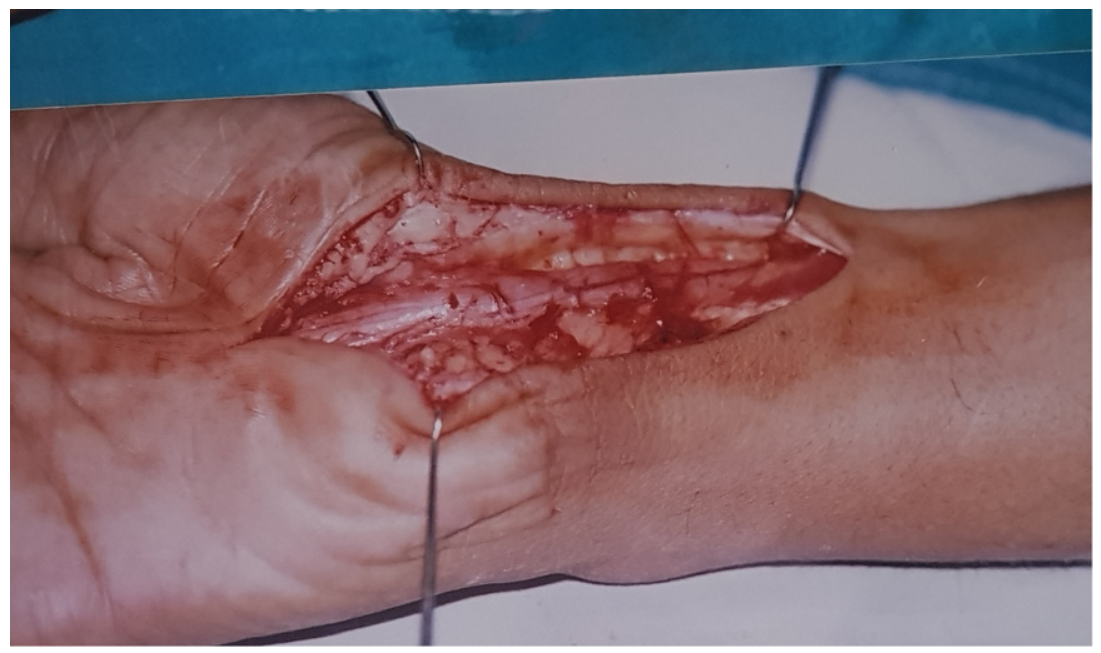

Figure 2. Epineurotomy of the median nerve.

Table 1. Profile of nerves included in the study ( 50 nerves of 36 patients)

\begin{tabular}{lcccc}
\hline & \multicolumn{2}{c}{ Unilateral } & Bilateral & Total \\
\cline { 2 - 4 } & Medical & Surgical & & \\
\hline Sex & 9 & 10 & 9 & 28 \\
$\quad$ Male & 9 & 8 & 5 & 21 \\
Female & & & & 17 \\
Classification & 10 & 11 & & 12 \\
$\quad$ Paucibacillary & 9 & 8 & & 22 \\
Multibacillary & 6 & 6 & & \\
$\quad$ Neuritic & & & & \\
\hline
\end{tabular}

Testing (ST). ${ }^{4}$ The VMT involved grading of the abductor pollicis brevis, opponens pollicis and the first lumbrical using the British Medical Research Council Grading (MRC Grading). The sum of the grades of these three muscles was expressed as the voluntary motor score. The maximum score was 15 .

Sensory testing was done at 15 predetermined sites over the median nerve distribution, and the total number of sensitive points was expressed as the Sensory score. Sensation was tested using No. 3 Nylon (0.38 in diameter). One point was given for each correct response to No. 3 Nylon, making a maximum score of 15 . No. 6 Nylon $(0.75 \mathrm{~mm}$ in diameter) was used only on those sites which showed misreference or no response to No. 3 Nylon. Half a point was given for each correct response to No. 6 Nylon.

The predetermined sites for sensory testing were: (1) On the volar aspect of the Index finger, two points each over the radial border of each phalanx and two points on the radial border of the palm were tested for a total of eight sites on the volar surface. (2) On the dorsal aspect of the Index finger, one point on the distal phalanx, two points each on the middle and proximal phalanges, and two points on the radial border of the dorsum of the hand were tested for a total of seven sites on the dorsum. 
Table 2. Classification of the nerve function impairment

\begin{tabular}{lclc}
\hline & VMT score & & Sensory score \\
\hline Grade 1 & $0-2$ & Normal & $13-15$ \\
Grade 2 & $3-6$ & Grade 1 & $10-12$ \\
Grade 3 & $7-9$ & Grade 2 & $7-9$ \\
Grade 4 & $10-12$ & Grade 3 & $3-6$ \\
Normal & $13-15$ & Grade 4 & $0-2$ \\
\hline
\end{tabular}

Table 3. Group A: pre and post medical treatment assessment

\begin{tabular}{|c|c|c|c|c|c|}
\hline \multicolumn{3}{|c|}{ Sensory assessment } & \multicolumn{3}{|c|}{ Motor assessment } \\
\hline Status & Pre-treatment & Post-treatment & Status & Pre-treatment & Post-treatment \\
\hline Normal & 0 & 9 & Normal & 0 & 9 \\
\hline Grade 1 & 5 & 6 & Grade 4 & 7 & 2 \\
\hline Grade 2 & 11 & 3 & Grade 3 & 13 & 8 \\
\hline \multirow[t]{2}{*}{ Grade 3} & 9 & 4 & Grade 2 & 2 & 3 \\
\hline & & & Grade 1 & 2 & 0 \\
\hline $\begin{array}{l}\text { Complete } \\
\text { sensory loss }\end{array}$ & & 3 & $\begin{array}{l}\text { Complete } \\
\text { motor loss }\end{array}$ & 1 & 3 \\
\hline Total & 25 & 25 & & 25 & 25 \\
\hline
\end{tabular}

Table 4. Group B: pre and post-surgical treatment assessment

\begin{tabular}{|c|c|c|c|c|c|}
\hline \multicolumn{3}{|c|}{ Sensory status } & \multicolumn{3}{|c|}{ Motor status } \\
\hline Sensory status & Pre-treatment & Post-treatment & Motor status & Pre-treatment & Post-treatment \\
\hline Normal & 0 & 16 & Normal & 0 & 18 \\
\hline Grade 1 & 6 & 8 & Grade 4 & 7 & 4 \\
\hline Grade 2 & 11 & 1 & Grade 3 & 13 & 3 \\
\hline Grade 3 & 8 & 0 & Grade 2 & 4 & 0 \\
\hline & & & Grade 1 & 1 & 0 \\
\hline Total & 25 & 25 & & 25 & 25 \\
\hline
\end{tabular}

Motor and sensory scores graded as 'good', 'moderate', 'bad' and 'absent or paralyzed' are shown in Table 2.

\section{Observation}

In group A, pain totally disappeared in two to three weeks. The intensity of pain started decreasing after $72-96 \mathrm{~h}$ and finally disappeared by two to three weeks. Results of nerve function are presented in Table 3.

In Group B recovery from pain was seen within $24 \mathrm{~h}$. Results of nerve function are presented in Table 4.

\section{Discussion}

Basically leprosy is a neurological disease. The median nerve is the second commonest nerve to be involved in leprosy. Most impairments, disabilities and handicaps in leprosy are due to neuropathy. Fibrosis of the epineurium (outer envelope of the nerve) leading to nerve 
enlargement causes an increase in the internal compartment pressure ultimately leading to ischemia and neuropathy. ${ }^{5-12}$

Pain is the commonly the first symptom to appear. It occurs in almost all the patients with carpal tunnel syndrome due to leprosy. This pain may become very disabling. ${ }^{4}$ We have seen that with medical treatment alone, pain takes 3-4 weeks to subside, while in group B (Surgical Group) it begins to subside within $24 \mathrm{~h}$. This is the biggest gain and the main indication for the surgical + medical approach.

Other authors have also noted quite impressive results following decompression of peripheral nerves. ${ }^{13-17}$

Steroid therapy is routinely used for neuritis in leprosy. ${ }^{18}$ The recommended dosage is $0.2 \mathrm{mg}$ to $0.5 \mathrm{mg} / \mathrm{kg}$ body weight while Wagenaar et al. ${ }^{19}$ have suggested oral prednisolone $45 \mathrm{mg} /$ day for patients with low weight $(50 \mathrm{~kg})$ and at $60 \mathrm{mg} /$ day for patients with high weight $\left(>50 \mathrm{~kg}\right.$ ), tapering over a period of time. An updated Cochrane review ${ }^{20}$ showed that corticosteroids are widely used for treating acute nerve damage in leprosy, but moderatequality evidence from two RCTs indicated that treating either longstanding or mild nerve function impairment did not show corticosteroids to have a superior effect to placebo on nerve function improvement. A third trial showed significant benefit from a five-month steroid regimen over a three-month regimen in terms of response to treatment (need for additional corticosteroids).

\section{Sensory improvement}

In our study, we have taken 25 cases for steroid treatment (Group A). Post-treatment assessment showed sensory improvement in 60\% (normal and Grade 1) from $20 \%$ (pre-treatment). These results are comparable with other studies. ${ }^{12,15,17,21-24}$

In group B, decompression along with steroids gave sensory improvement in $96 \%$ (normal and Grade 1) from 24\% (pre-treatment). These results are similar to other studies for surgical decompression of neuropathies. ${ }^{15,16,25}$

\section{Motor improvement}

Of the 25 cases given steroid treatment (Group A), assessment showed improvement from no cases with normal strength pre-treatment, to $36 \%$ (9/25) post-treatment.

In group B, motor strength improved from no cases with normal strength pre-treatment, to $72 \%(18 / 25)$ post-treatment.

\section{Conclusion}

From our observations it can be said that for median nerve involvement in leprosy, surgical along with medical treatment is a better choice in comparison with a solely medical or chemotherapeutic approach. All the three components of nerve damage, including pain, sensory and motor loss, improved more quickly and more completely in the second group, which provided a surgico-medical approach, applied at the right time. This also helps in preventing progression to secondary deformities. Hence we advocate that steroids along with surgical decompression of the median nerve is a better strategy for the treatment of median nerve neuritis in leprosy cases.

At the same time, the role of early diagnosis also needs to be emphasized. The authors recommend that during the examination of each patient, nerve tenderness should be tested as a routine measure, even if the patient does not complain of it. 


\section{Acknowledgements}

The authors declare no potential conflicts of interest with respect to the research, authorship, and/or publication of this article. No financial aid/support of any kind was received from any individual/organization for this study. Institutional Review Board approval was given, with reference: FHMC/EC/14/2015. Pre-surgical consent was taken prior to surgery.

\section{References}

1 Hansen GA, Looft C. Leprosy: in Its Clinical and Pathological Aspects. London, Bristol: John Wright \& Co, 1973; pp. 50-51, 123, Plates XI, XII.

2 Silveira LM. Tratamento cirúrgico das neurites leprosas agudas. Rev Bras Leprol, 1938; 6(n. especial): 193-196.

3 Kiran KU, Stanley JNA, Pearson JMH. The outpatient treatment of nerve damage in patients with borderline leprosy using a semi-standardized steroid regimen. Lepr Rev, 1985; 56: 127-134.

4 Lewis S. Reproducibility of sensory testing and voluntary muscle testing in evaluating the treatment of acute neuritis in leprosy patients. Lepr Rev, 1983; 54: 23-30.

5 Girdhar BK. Neuritic leprosy. Indian J Lepr, 1996; 68: 35-42.

6 Antia NH. The significance of nerve involvement in leprosy. Plast Reconstr Surg, 1974; 54: 55-63.

7 Carayon A, Giraudeau P, Disy P. La composante neuro-vasculaire dansles ulceres plantaires de la lepre. Med Trop, 1978; 38: 453-478.

8 Job CK, Victor DBI, Chacko CJG. Progressive nerve lesion in a diseasearrested leprosy patient. An electron microscopic study. Int J Lepr, 1977; 45: 255-260.

9 Mahajan PM, Jogaikar DG, Mehta JM. A study of pure neuritic leprosy: clinical experience. Indian J Lepr, 1996; 68: 137-141.

10 Palande DD, Bowden REM. Early detection of damage to nerves in leprosy. Lepr Rev, 1992; 63: 60-72.

11 Rose P, Waters MFR. Reversal reactions in leprosy and their management. Lepr Rev, 1991; 62: 113-121.

12 Palande DD, Azhaguraj M. Surgical decompression of posterior tibial neurovascular complex in treatment of certain chronic planter ulcers and posterior tibial neuritis in leprosy. Int J Lepr, 1975; 43: 36-40.

13 Muir E. Manual of Leprosy. Edinburgh: Livingstone, 1948; pp. 137-138.

14 Husain S, Mishra B, Prakash V, Malaviya GN. Results of surgical decompression of ulnar nerve in leprosy. Acta Leprol, 1998; 11: 17-20.

15 Pandya NJ. Surgical decompression of nerves in leprosy: An attempt at prevention of deformities: A clinical electrophysiologic, histopathologic and surgical study. Int J Lepr Other Mycobact Dis, 1978; 46: 47-55.

16 Oommen PK. Posterior tibial neurovascular decompression for restoration of planter sweating and sensibility. Indian J Lepr, 1996; 68: 75-82.

17 Droogenbroeck van JB, Naafs B. Posterior tibial release and arteriolysis in leprosy. Med Trop, 1977; 37: 777779.

18 Cochrane RG, Davey TF. Leprosy in Theory and Practice. London, Bristol: John Wright and Sons, 1964. $41,259,265-80$.

19 Wagenaar I et al. Effectiveness of 32 versus 20 weeks of prednisolone in leprosy patients with recent nerve function impairment: A randomized controlled trial. PLoS Negl Trop Dis, 2017; 11(10): e0005952. doi:10.137 1/journal.pntd.0005952. eCollection 2017 October.

20 van Veen NHJ, Nicholls PG, Smith WCS, Richardus JH. Corticosteroids for treating nerve damage in leprosy. A Cochrane review. Cochrane Database Syst Rev, 2016; 23(5): CD005491. doi:10.1002/14651858.CD005491. pub3.

21 Husain S, MIshra B, Malaviya GN. Evaluation of results of surgical decompression of median nerve in leprosy in relation to sensory-motor function. Acta Leprol, 1997; 10: 199-201.

22 Parikh AC, Ganpati R, Kothare KB, Divekar SC. Decompression of ulnar and median nerves in leprous neuritis. Lepr Rev, 1968; 39: 143-146.

23 Srinivasan H, Rao KS, Shanmugam N. Steroid therapy in recent 'Quiet Nerve Paralysis' in leprosy. Lepr India, 1982; 54: 412-419.

24 Van Brakel WH, Khawas IB. Silent neuropathy in leprosy: an epidemiological description. Lepr Rev, 1994; 65: 350-360.

25 Srinivasan H. Prevention of Disabilities in Patients with Leprosy: A Practical Guide. Geneva: WHO, 1996. 